\title{
The Seven50 Plan and Regional Governance in Southeast Florida
}

\author{
Ramon Trias ${ }^{1}$, Jean-Claude Garcia-Zamor ${ }^{2}$ \\ ${ }^{1}$ Planning and Zoning, Coral Gables, Florida, USA \\ ${ }^{2}$ Florida International University, University Park, Florida, USA \\ Email:garciazamor@hotmail.com
}

Received 30 September 2015; accepted 2 November 2015; published 5 November 2015

Copyright (C) 2015 by authors and Scientific Research Publishing Inc.

This work is licensed under the Creative Commons Attribution International License (CC BY). http://creativecommons.org/licenses/by/4.0/

(c) (1) Open Access

\begin{abstract}
This article provides an introduction to "Seven50: Southeast Florida Prosperity Plan", including project design, public process and recommendations. Seven 50 was a regional discussion about the next 50 years of development for seven counties. The project was executed from 2009 through 2014. The principal author of the article was a member of the Seven50 Executive Committee from the start to the end, and participated in the debates about its goals, chronology and professional activities. Research and analysis were performed on the final deliverables of the project. In addition, qualitative interviews were conducted with key participants in March and June of 2015, approximately a year after the project was completed. Their views and opinions provided context for an evaluation of the project's effectiveness and its impact on future regional growth. Conclusions were reached about the value of the process and its contribution to the theory and practice of regional planning and governance.
\end{abstract}

\section{Keywords}

Regional Planning, Sustainable Communities, Better Governance

\section{Introduction}

Public administrators and town planners often believe that growth and development should be planned at many scales, from the neighborhood to the town, the region and even the state. This belief has resulted in public planning projects designed to gather data and propose policies that would guide implementation of preferred town planning and economic development goals. In states where fast growth was anticipated, such as Florida, development was often a source of concern in debates about future quality of life. Although long-term residents and newcomers often spoke of South Florida and the Treasure Coast as paradise, change was expected. Enhanced 
regional planning, to mitigate the impacts of change, had been a recurrent aspiration for civic leaders and top administrators since the mid-twentieth century. Interested citizens had been asked multiple times to brainstorm and collaborate, with mixed results. This article discusses a recent regional planning project known as "Southeast Florida Prosperity Plan" (Seven50), from the point of view of key participants and public administrators tasked with the execution of the project, one year after the end of the process.

\section{Research Methodology}

The principal author of this article was a member of the Seven50 Executive Committee. Some of the content of the article is based on personal experience and observation of the process. Primary research was performed on all public deliverables, such as printed documents and web based information created during the planning activities and submitted as final products. In addition, qualitative interviews with key participants were held in March and June of 2015, approximately a year after the completion of the project.

Seven key participants and project leaders were interviewed. These included the initial Project Director, the Executive Directors of two Regional Planning Councils, the Chairman of the Executive Committee, and three professionals who were part of the team of consultants. Although the people who were interviewed work in several of the counties involved in the project, most of the interviews were conducted before or after various meetings of The Treasure Coast Regional Planning Council. The principal author of this article sat with each one of them for lengthy conversations regarding their roles and evaluations of the project. The names and positions of each one of them are listed in the endnote at the end of the paper. These individuals were collectively responsible for the organization and execution of the project and were expected to have a role in future implementation of the recommendations. Their comments and insights are summarized throughout the article, in an effort to provide context to the process and opinions about its success or failure. In addition, Seven50 was evaluated as a case study of the application of regional planning theory and as a project that would advance ideas about regional governance.

\subsection{On a Mission to Redefine Paradise}

The mission of Seven50 fit the grand narrative of paradise found:

"Seven50 (Seven counties, 50 years) is a blueprint for growing a more prosperous, more desirable Southeast Florida during the next 50 years and beyond. The plan is being developed to help ensure a vibrant and resilient economy, and stewardship of the fragile ecosystem in what is quickly becoming one of the world's most important mega-regions."

Nevertheless, the back cover of the plan would highlight four words: "Better Region. Better Life," which would suggest a preference for reflection and change, in anticipation of rapid growth. In recent decades, daily life in Southeast Florida had been stressed by development. But concerns about traffic, sustainability, climate and the economy pointed towards an uncertain future. Thus, Seven50 was to be a public discussion about expectations and challenges, vision and experience, aspirations and the hard work of getting things done. Current development trends were inconsistent with paradise, and there was a wish that in the next 50 years, the seven counties in Southeast Florida should grow in better ways that in the last few decades, which produced considerable sprawl, urban disinvestment and poor public planning.

\subsection{Background for a Better Plan}

Seven50 was a partnership of two Regional Planning Councils (RPC), South Florida and Treasure Coast, which secured a competitive grant of $\$ 4.25$ million from the U.S. Department of Housing and Urban Development's Sustainable Communities initiative, in order to create a plan for economic prosperity. Therefore, Seven50 was expected to generate considerable public interest in an area of the country that had pioneered regional growth management and enjoyed a respected track record of successful public planning projects. Moreover, with Regional Planning Councils established in their present form in 1976 through inter-local agreements among counties, there was an experienced administrative infrastructure in place with a multipurpose mandate, ready to pursue implementation.

Seven50's conversations were expected to result in a voluntary strategic plan for use by the public and private sectors. The scope of the project included counties located along the Atlantic Coast of Southeast Florida: Monroe, 
Miami-Dade, Broward, Palm Beach, Martin, St. Lucie, and Indian River. Southeast Florida was not yet a commonly used term. South Florida and Treasure Coast were the vernacular regional names. Seven50 proposed a new perspective of geography, to reflect contemporary trends in the economy. However, not every participant agreed that such trends were real or even desirable.

Moreover, some areas under study were very urban, such as Miami, and other locations were generally rural, such as the western portions of Palm Beach, Martin, St. Lucie and Indian River counties. The timeframe was fifty years, an eternity in an area of the world known for swift transformation, time and time again, during a century of urban development. Findings from the interviews revealed some initial concerns about the scale of Seven50. But no fundamental questions arose about its conceptual framework, in terms of scope or time span.

\subsection{Towards a Theory and Practice of Regional Planning in Florida}

Contemporary regional planning theory recommends a coordinated multidisciplinary approach, at different scales. Barnett (2000) edited a book with other experts from various fields of public policy, and attempted to define a theoretical basis for regional planning at the start of the twenty-first century. A core proposition was that local codes would create or fix regional problems, depending on the content and efficiency of the administrative framework. Calthorpe and Fulton (2001) discussed comparable ideas from the point of view of town planning solutions, such as transit oriented development and linkages between land use and transportation policy. Later, Calthorpe (2011) addressed the consequences of larger scale conditions, such as climate change, a topic of particular interest for Southeast Florida. Thus, the literature suggests that better regional planning would not result from large scale economic or social policy solutions only, but from a more strategic conception and simultaneous application of effective land use regulation at the level of the city, town or neighborhood. In addition, throughout the 1990's, Barnett, Calthorpe and others had used Florida as an empirical laboratory through work on several regional projects.

Comparable ideas had been expressed in the mid 1990's in the Charter of the Congress for the New Urbanism, which stated that the metropolitan region was the fundamental economic unit of the contemporary world, and promoted enhanced governmental coordination. Moreover, the American Planning Association, a private organization that promotes the profession of planning, had proposed standardized procedures for preparation and adoption of regional plans. More recently, Duany, Speck and Lydon (2010) also recommended a planning process that would begin with mapping regional assets and progressively lead to carefully designed neighborhoods. Their book was formatted as a manual for practice and composed of brief single issue chapters, intended to be applied sequentially, according to the specific needs of each project.

Although the overall goal of multijurisdictional coordination over a large but well-defined geographical area had been accepted in public administration practice for several decades, there were contrasting opinions on an effective methodology for regional planning, and for an evaluation of success. For example, some discussions emphasized public participation, in an effort to promote more democratic decisions, but often neglected content. Other times, regional planning projects were misunderstood as the largest projects within the boundaries of a single discipline, whether it may be transportation, housing or preservation of environmental systems. In contrast, Seven50 intended to involve the public, cross disciplines and find lasting efficiencies, as suggested by the Sustainable Communities initiative, current regional planning theory and best professional practices. Interviews with project leaders demonstrated an awareness of the need to expand the limits of past efforts and an interest in practical applications. Even though the scope of the project appeared very ambitious, all the participants interviewed found it appropriate, as a logical step in local and county efforts to better coordinate growth management decisions.

An interesting finding from the interviews was that the project was not perceived in isolation, but as part of a succession of regional planning activities that had been performed for the past 25 years. Some had catchy names, such as Eastward Ho, a pioneering regional planning effort performed in the 1990's, which led to increased interest in urban infill and investment in transit in South Florida. Many of the Seven50 participants were veterans of earlier projects, and some recognized the relatively modest outcomes from past planning efforts. However, although there was a general belief that regional planning was useful, success of implementation efforts upon completion of a regional plan had not been evaluated. Systematic research of the effectiveness of regional planning in Southeast Florida was yet to be performed, and lack of data presented a challenge for project design. 


\subsection{Office of Sustainable Communities, Department of Housing and Urban Development}

In 2009, the office of Sustainable Communities of the Federal Department of Housing and Urban Development (HUD) initiated a program for the preparation of regional plans that would integrate housing, land use, economic and workforce development, transportation and infrastructure investment into a long-term vision of partnerships for development and reinvestment. Related programs within the Federal government had been administered in the past with staff from HUD, the Department of Transportation and the Environmental Protection Agency. The Sustainable Communities program proposed a comprehensive, multidisciplinary approach to regional planning.

The Sustainable Communities program attempted better coordination for Federal policy and encouraged enhanced governance at the scale of the region, through a competitive grant program for planning and project implementation. The content of the effort was directly influenced by regional planning concepts proposed by the Congress for the New Urbanism, Duany, Barnett, Calthorpe and related practitioners. Thus, theory of regional planning and governance were ready to be tested in Southeast Florida in 2010.

\subsection{The Path toward Seven50}

Regional Planning Councils were the only general planning organizations in the public sector in Florida at a multijurisdictional scale. Other public organizations that spanned across several jurisdictions, such as Metropolitan Planning Organizations (MPO's) or districts of the state Department of Transportation (FDOT), were specialized agencies with targeted missions. On the other hand, Council members were a mix of county and local government commissioners and gubernatorial appointees, assisted by competent professional staff, tasked with thinking strategically about the future. The Councils enabled local governments and citizens to debate and coordinate comprehensive solutions to complex interrelated issues that affected more than one jurisdiction. Most issues related to growth affected many people, in different ways. The existing public administration framework encouraged regional coordination.

In 1992, The Treasure Coast Regional Planning Council adopted an innovative Strategic Regional Policy Plan that attempted to define preferred forms of development. Up to that point, regional plans had followed the Comprehensive Plan format, where separate elements addressed specialized topics (Transportation, Housing, Water Supply, etc.). The Treasure Coast RPC's Strategic Policy Plan included an optional “Vision” element which attempted to provide a cohesive set of policies for sustainable growth, which were summarized in strategies to develop and redevelop “Towns, Villages and the Countryside.” This proactive approach based on preferred scenarios was unprecedented in regional plans for Florida. As the region grew during a boom at the end of the twentieth century, the Strategic Regional Policy Plan was used for project review and educational purposes. In some cities and counties, regional policies were implemented at the local level with innovative form-based codes. One example was the "TVC" (Towns, Villages and Countryside) land use and form-based code for north St. Lucie County adopted in 2006, which implemented goals of the Treasure Coast Strategic Regional Plan.

The Treasure Coast RPC had established an urban design studio in 1991, which was staffed through the years with design professionals with expertise in public participation. Professional staff from the Council often advised municipalities and provided technical assistance, through the organization of charrettes and preparation of zoning code amendments. In an effort to enhance regional visioning and governance, since the late 1990's, the Treasure Coast RPC had provided technical assistance to the South Florida RPC in the form of staff support for charrettes and visioning sessions in communities throughout Miami-Dade county. Collaboration with local governments in need of technical assistance became one of the best known activities of the Council. This effort identified the need for a more structured regional vision. Discussions between the Michael Busha, Executive Director of the Treasure Coast RPC and Carolyn Deckle, Executive Director of the South Florida RPC led to collaboration of the Seven50 project in 2009.

The untimely death of the executive director of the South Florida RPC as the Seven50 project got underway presented significant administrative challenges. A new executive director was hired. He immediately hired a project director, well-regarded planner Jim Murley, a former Secretary of the Florida Department of Community Affairs. Soon after, the new director left, and the South Florida RPC appointed Mr. Murley as executive director. He would function on this dual role at the start of theSeven50 process. Both Executive Directors provided initial leadership for Seven50, and conceptualized the project with the participation of interested citizens such as Tom Gustafson, a former Speaker of the Florida House of Representatives and early member of the Executive Committee. 


\subsection{Seven50 Timetable}

By February of 2010, the South Florida Regional Planning Council and the Treasure Coast Regional Planning Council signed a memorandum of understanding to form the South Florida Regional Partnership. The Partnership would grow, as local governments, NGO's, businesses and non-profits joined the effort. The Partnership submitted a grant application to the Department of Housing and Urban Development in August of 2010.

In October of 2010 the Partnership was awarded \$4,250,000.00 to create a regional plan for sustainable growth. Requirements were flexible, as the program encouraged each recipient to design and calibrate the plan according to local needs. By November of 2010 the Partnership had defined the goal of a "regional vision for economic prosperity". A project management team, mostly composed of staff from the Regional Planning Councils, and an Executive Committee, with membership spanning the partnership organizations, was established.

In October of 2011 a consulting team was selected. It was led by Dover, Kohl and Partners with support from additional firms, such as Duany, Plater-Zyberk and Company. By June 2012, the first public meetings were held, and the project was named "Seven50: Southeast Florida Prosperity Plan". From then on, it would be generally known as Seven50, a clever suggestion by branding experts from the consultant team.

\subsection{The Design of Seven 50}

The process, content and products of Seven50 were integrated from the start. The plan would be an exceptional process of synthesis, were parallel discussions on public engagement, research data, preferred scenarios and implementation would illustrate that a better future would require iterative work, professional expertise and administrative conviction. Seven50 was designed to be directed by Regional Planning Council staff, with a leadership group composed of the Executive Directors of the RPC's, a project director, a partnership coordinator and policy analysts. This core staff group provided support to the Executive Committee and managed the work of the consultant.

The organizational framework was provided through bi-monthly meetings of the Executive Committee, a volunteer group composed of board members of the two Regional Planning Councils at first, and which would growth to 32 members and would reflect the diversity of people, organizations and ideas of the region. The Executive Committee provided general direction and debated policy. The meetings of the Executive Committee were open to the public. They were held at the office of the Broward County Metropolitan Planning Organization, located near a Tri-Rail station and also Interstaet-95. Many members took the commuter train to attend.

The public participation process was structured around four Summits. They were scheduled in locations in four counties, from June of 2012 to January of 2014. The Summits were intended to be cumulative and lead to the unveiling of the Plan. Additional opportunities for public input included workgroup road shows, travelling workshops, interactive asset mapping, a data warehouse, an online scenario modeler, public broadcasts and social media. Content was developed continuously, with the objective of producing a toolkit with recommendations at all scales of development. The products would evolve through the process, as a result of debates by the Executive Committee and direction from staff. In the end, process, content and product were summarized in 333 pages of a copiously illustrated book, printed on demand and ordered on the Seven50. org website, at a cost of $\$ 69.48$.

Seven50 was described as a process, a tool, a vision and a goal. This conceptual framework for regional planning attempted more than a general "vision". Recent theoretical work recommended strategies of participation and implementation, which should be incorporated in the design of the project from the start. The Executive Committee and staff established priorities which emphasized the integration of vision, public input and work products.

\section{The Summits}

On June 27 of 2012, the first of four Summits was held in Old School Square in Delray Beach, Palm Beach County. Delray Beach was a small historic coastal city which had enjoyed well-known success in multiple redevelopment and infill projects since the early 1990's. The venue for the meeting was Old School Square, an outstanding example of historic preservation and high quality urbanism. Over 500 people attended.

Presentations from consultants and officials explained the process and provided initial ideas about opportuni- 
ties. Afterwards, everyone participated in a large focus group to determine priorities. This event was reminiscent of public design workshops common during planning charrettes. The prospect of planning for the next fifty years did not overwhelm the participants. The crowd appeared comfortable, as if planning for the next fifty years were a routine event. The Summit may have been promoted as a unique opportunity to guide the future, but most participants were generally familiar with the format and many were veterans of past regional planning efforts.

Part of the message from the consultants was that fifty years was a very long time for Southeast Florida. A century ago, the region was wild, wet and flat, with few people. In the early twenty-first century, the region had urbanized, nature was managed by engineers, and several million people lived within a few miles of the sandy beaches of the Atlantic coast. Millions of visitors would come every year. The assumption of steady growth was at the core of any planning process.

One hundred people per week were expected to move to the region, for the next five decades. Every few years, the accepted narrative about the region, the state, or even each city, had to be renewed, as new people arrived from multiple places is the world, and they were unfamiliar with the region's recent past. However, a common component of successive narratives was a belief that better regional planning would preserve paradise. In the focus groups, there was considerable talk on this general theme. After a day of discussion, the Summit was adjourned.

For the six months that followed the first Summit, staff from the Regional Planning Councils and the consultant team refined the Seven50 work plan. The Executive Committee met regularly. Staff reported on the progress of the project during Council meetings and in additional meetings and workshops with individuals and organizations interested in regional cooperation. Nevertheless, in spite of active communication efforts, it became apparent that the work plan had underestimated the requirements of effective outreach.

A second Summit organized on January 24, 2013, with over 300 people in attendance. It was held at Miami-Dade College's downtown Miami campus, in Miami-Dade County. A large map of the region greeted the participants at the entrance of the auditorium. Everyone was encouraged to mark it up, with suggestions. Photographs of this activity would be posted on the Seve50 website, as a visual demonstration of the process of public input. However, as the project developed over three years, the map itself would not be included in the final deliverables. Consensus about the future of the region had proved elusive.

\subsection{An Aspirational Region, with Better Governance and Governability}

The proposition that the seven counties of Southeast Florida formed a cohesive region was questioned from the start, and became a recurrent subject of dispute. There were valid reasons to reject this fundamental assumption. Participants from the northern counties wondered if they had anything in common with southernmost counties, and made sure their opinions were heard. At first, officials from Miami-Dade County participated sporadically. On the other hand, representatives from the Department of Transportation were very involved and supported the regional outlook, as professional staff had realized in recent times that building roads in isolation of other considerations did not create quality communities. Furthermore, Broward County officials were very active on issues regarding sea level rise, as county staff had negotiated a climate compact. Thus, contrasting ideas about a common future among neighbors predated Seven50 and continued through the process.

But a common future required consensus, and some participants believed at the conclusion of Seven50 that communication and coordination efforts could have been more effective. Early on, project leaders appeared to believe that the value of regional planning was self-evident. For the public at large, however, regional planning was a new topic. In the opinion of several participants interviewed, Seven50 did not sufficiently emphasize early partnerships and outreach, to the detriment of the later stages of the project, and ultimate official support. These were important issues for HUD's office of Sustainable Communities. The local Executive Committee, professional staff and consultant team were expected to calibrate the work program to the needs of each geographic area. During the Seven50 process it became apparent the greatest need was an answer to the question: are these particular seven counties a region? Either a deliberate yes or no would have been valuable.

\subsection{The Plan}

The main deliverable from the consultant (the Plan) was a document that summarized the findings from the public participation process and provided recommendations for policy direction at all levels of public administration and governance, from homeowners associations to the Federal bureaucracy. The document was designed for use 
in the website and as a printed publication, and compiled research data, big picture ideas and targeted tools in a highly graphic format that would be readily accessible to the reader and encourage creative linkages among diverse topics. The analogy of the "blueprint for growth" used in the mission statement held true. The plan was driven by data depicted at multiple scales in a coordinated way, similar in organization to a set of construction documents or "blueprints." Some sections of the document dealt with details, some pages tabulated information, other pages summarized larger scale concerns. As with architectural blueprints, information was intended to be read in context and comprehensively. Each detail contributed to the understanding of the whole, and was complete in itself. Therefore, the tools at any given page could be applied individually, with the certainty that the use of many tools by many people would lead to a better region. This incremental approach was consistent with current theory on regional planning.

The core content of the plan centered on description and analysis of preferred scenarios for the next 50 years. A comparison of comprehensive options of development, with a public process to determine preferences, was an accepted methodology for regional planning. A similar process had been used to prepare the Strategic Regional Policy Plan of 1992.

Four scenarios summarized major policy alternatives (Figure 1):

1. Stay the course. This scenario reflected no changes in policy. Generally, it could be described as a continuation of development trends that resulted in sprawl, with minimal components of conservation and farmland. This proposal received support from $4 \%$ of participants.

2. Suburban expansion. In this case, growth would be master-planned according to suburban principles, with considerable environmental benefits. However, urban development would continue to be oriented towards the automobile. A significant minority, $19 \%$ of participants, supported this scenario.

3. Strategic upgrades. This approach can be best described targeted infill, within existing cities. Urban areas would be planned precisely, to encourage better mix of land uses and building types. Only $4 \%$ of participants believed this option was the best alternative.

4. Region in motion. This was the preferred alternative. This scenario linked transportation and land use, with emphasis on urban infill and environmental conservation. Public support for this comprehensive alternative demonstrated a willingness to take significant policy action that would result in a different pattern of development. A large majority of the participants, $73 \%$, selected this scenario.

\section{PREFERRED SCENARIO BETTER REGION. BETTER LIFE.}

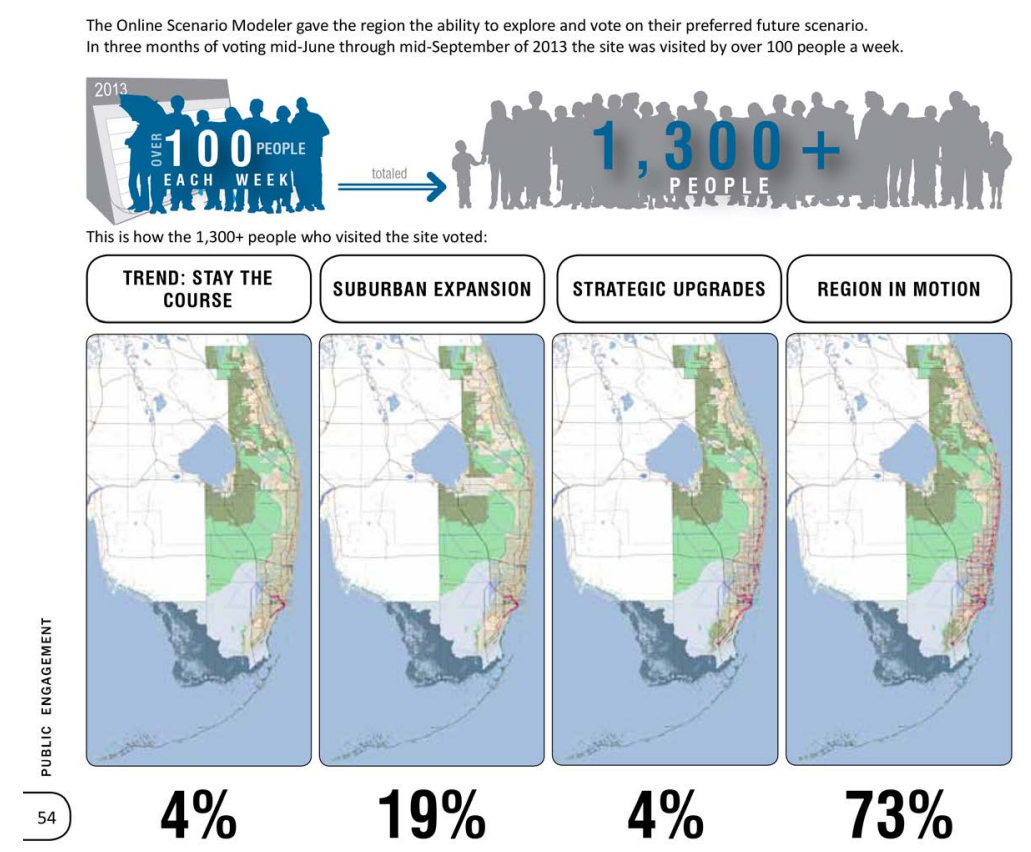

Figure 1. Development scenarios. Note: from "Seven50 Plan”. 
The Region in Motion scenario was representative of recent policy preferences. For the better part of two decades, transportation had guided a majority of policy discussions about growth in Florida. Early on, transportation discussions were limited to the use of automobiles. Later, as congestion proved a greater challenge than predicted by traffic engineering models, conversations shifted towards a more inclusive study of preferred development scenarios. Better solutions would depend on the coordination of land use choices, patterns of urban design and availability of multiple transportation choices. The core would be structured around a walkable community.

In the final document, the preferred scenarios were displayed in one page, side by side. Each scenario was evaluated based on the following indicators:

1. Farmland consumption

2. Infrastructure cost (transportation, water, sewer and utilities)

3. Single family homes vs. condominiums, apartments and townhouses

4. Transportation choices

5. Walkable communities (walk to work, school, stores, transit, park)

6. Average housing and transportation costs as a percentage of household income

7. Climate resilience investment

The analysis was general and intended to suggest trends. However, some amounts and percentages were displayed to quantify the scope of each policy choice. For example, the infrastructure costs for the Region in Motion scenario were high, approximately $\$ 24$ billion. However, the costs associated with development predicted under the Stay the Course alternative were even higher: \$31, 4 billion. Thus, participants were able to weigh the relative value of the policy choices, side by side.

The Region in Motion scenario concluded that $\$ 2.3$ billion would be saved in new roads, the percentage of income spent on housing and transportation would be lowered to 17\%, 2.2 million less car trips would be made, and there would be an increase of employment for artists of $1.54 \%$ (Figure 2). The accuracy of some of these predictions could be argued, and the indicators reflected early twenty-first century concerns. However, predictions for the future were based on trends that would affect quality of life. Policy alternatives were clearly explained with graphics. At a glance, a casual reader could discover topics that would affect lifestyles for decades

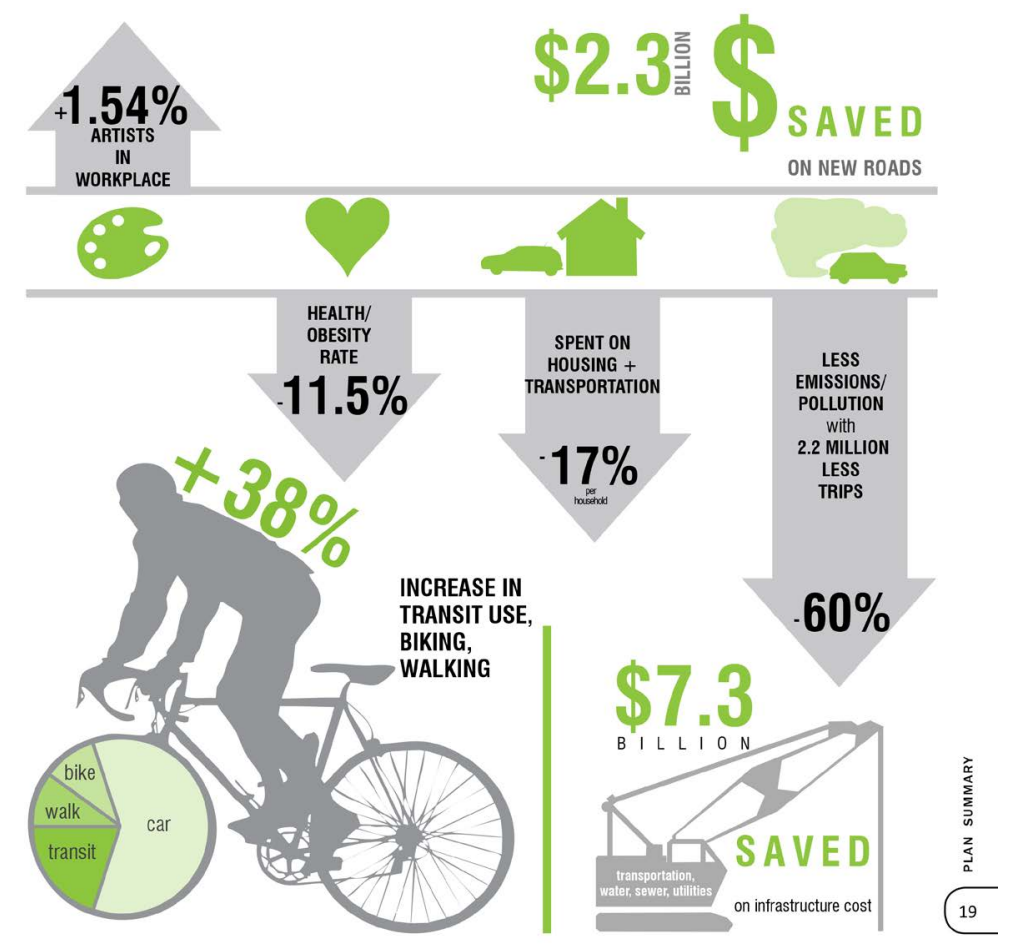

Figure 2. Infrastructure savings graphic. Note: from “Seven50 Plan”. 
to come (climate change, sprawl, redevelopment, agriculture, energy, affordable housing, water use, etc.). The Seven50 plan attempted to establish, for the first time, shared standards that defined the public values of the region. Unfortunately, values proved to be diverse across the region, with critical distinctions based on geography.

Seven50 created graphic tools to display public information, for use for planning and development. For example, future infrastructure costs would depend on the preferred development scenario. Increase of walking and bicycling would result in savings on road construction, under a scenario that emphasized compact development. As the plan would not have regulatory authority, education and communication were the primary goals.

Implementation of a preferred alternative, however, would require significant retooling of public administration activities. One early outcome of the Seven50 effort was the creation of a single transportation model for the region. Florida Department of Transportation participants realized from discussions with local officials that such a useful planning tool had never been prepared in the past. As discussions proceeded, additional opportunities for coordination in education, climate change and project development were identified.

\subsection{An Aspirational Region, toward Better Governance and Governability}

A topic of special interest was regional governance. In the second half of the twentieth century, as urban development accelerated throughout Florida, multiple public organizations attempted to provide direction. For example, there were 121 local governments in Southeast Florida in 2015. In Miami-Dade County alone there were 35 municipalities. Broward and Palm Beach included 31 and 38, respectively. However, the other four counties ranged from five to three. This distinction may have contributed to the interest and participation in the Seven 50 process. Counties were governance was most complex demonstrated less interest in Seven50, perhaps because people in the southern counties had enough administrative challenges, as some interviewees observed. The counties on the northern half of southeast Florida, were governance was relatively clear, had no interest in becoming similar to the south. Their representatives participated actively, at times in favor and at other times in opposition to the project.

In addition to the local governments, there was an intricate web of agencies and councils, which at times had conflicting responsibilities and incomplete perspectives. There were transportation authorities, metropolitan planning organizations, county-wide transit agencies, housing departments, county-wide school districts, and environmental agencies, all with their own board of directors, at times elected by the voters or appointed in a political process. Moreover, there were two regional planning councils and three metropolitan urbanized areas. Multiple entities had overlapping jurisdictions and redundant responsibilities. Here, some guidance from theory of regional planning on the topic of efficient governance would have been useful. However, the administrative infrastructure had been established through the twentieth century, with emphasis on specialization. Bureaucracy would not easily change. The intent of Seven50 was to propose areas of where governance could evolve towards synergy, once quality information about conditions, goals and tools was available (Figure 3).

The first step was a clear picture of existing conditions.Seven50's tabulation of components of regional governance was a valuable contribution, as it clarified the extent of the challenge. In fact, it could be said that regional planning aspirations for Southeast Florida should focus on a better understanding of the path to efficient leadership through better governance.

An important concept introduced by Seven50 was "subsidiarity”. This theoretical concept of governance assigns decision-making authority to the most appropriate and competent entity. It was analogous to the "urbanrural transect”, a core idea of new urbanism theory which proposed that all types of uses are needed and are valuable in a community, as long as they are organized spatially in the optimum location, relative to one another. A subsidiarity matrix was prepared which classified topics (climate change, natural systems, agriculture, infrastructure, etc.) according to the best level of authority, with a spectrum of choices that would range from the region to the person. For example, a person could do little about climate adaptation strategies but could participate in mitigation.

The 43 pages of the subsidiarity report posted on the Seven50 website were full of ideas, detail and recommendations developed during months of professional work. But Seven50 did not fully elaborate this critical subject. Unfortunately, discussion on governance became a principal source of friction among participants, and the final edits of the plan reduced the topic to three pages and four tools towards the end of the book, which offered some general advice on inclusive leadership.

Seven50 depicted the multiple views of quality of life and prosperity that coexisted in the region, in ways that would lead to conflict should governance remain unchanged. The core partnership of participants in the project, 


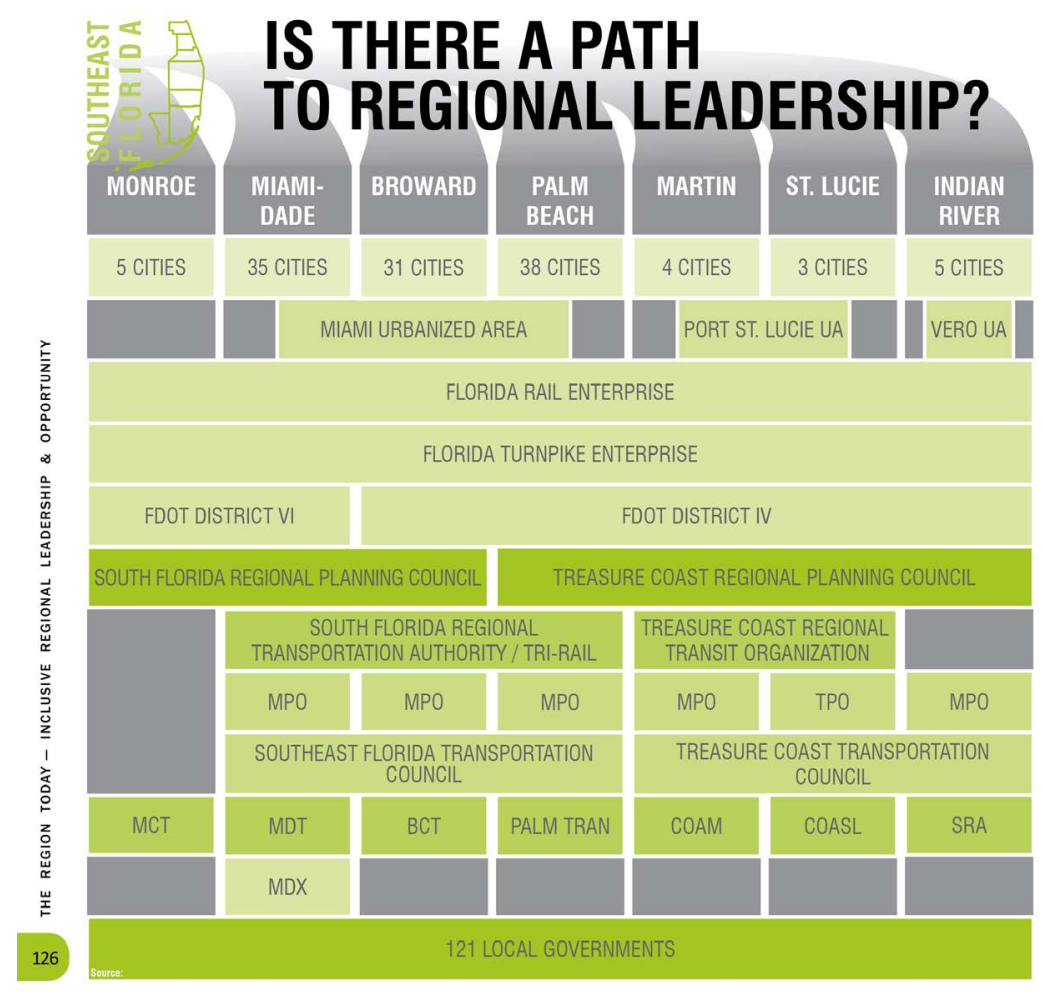

Figure 3. Governance table. Note: from “Seven50 Plan”.

the consortium, grew in membership during the project to 46 by February of 2014. It included a wide range of counties, cities, universities, business groups and non-profits, which had an interest in some or all the aspects of the plan. A few early successes were listed the Plan (a seven county transportation model, the regional data warehouse, the civic and leadership asset map, and a few prior initiatives that had become part of the process, such as the climate compact and inundation assessment). The partnership had the potential to continue the work initiated during Seven50, should the conversation continue.

\subsection{Strengths of the Process}

The shared opinion of participants interviewed was that the fundamental strength of Seven50 was public discussion. Representatives from diverse counties spent several years working on a common project. Many participants were skeptical at first. Some remained skeptical for the duration of the process. A majority, however, actively collaborated. Everyone had a chance to speak and listen, and project leaders believed that the various formats and locations promoted communication.

Another strength was the ability to summarize information into a practical toolkit. Project consultants were able to distill effective strategies for implementation, out of input that would appear unmanageable at first. For instance, illustrations of adaptation strategies for climate change translated an abstract concept into practical guidelines for preserving communities. On the opposite end of the spectrum of tools for the future, recommended design techniques for the proper screening of urban parking could be used by local governments interested in redevelopment.

In addition, neighboring local governments and agencies discussed opportunities to coordinate. In particular, good examples of policy initiatives were shared, such as the climate compact led by Broward County, or transportation modeling that could be applied across political jurisdictions. Public sector participants had a rare chance to explore creative solutions within a structured and facilitated process.

\subsection{Limits of the Process}

Seven50 demonstrated that regional planning lacked effective theoretical guidance. The interviews with project 
staff and consultants stressed interest in developing the right process, but there was a sense that effective models were not available. Thus, much effort and discussion was spent on organization and operation, to the detriment of time spent on research, findings and recommendations.

Moreover, it was never clear that the area under study was one region. The intersection of geography, development, culture and change proved to be a very complex mixture. Seven50 would have benefited from more rigorous research methods. A majority of the content was developed qualitatively, in meetings, interviews and focus groups. However, consultants often spent excessive amounts of time introducing the project, which left limited time for input from participants during public meetings. Qualitative data was gathered in unstructured ways, which opened the process to criticism. Furthermore, quantitative research was also handled informally. Data was provided in the form of maps or graphics which summarized provocative ideas. However, there were few attempts at explaining the source or methodology.

Some interviewees expressed disappointment with specific communication missteps. For instance, during the second summit in Miami on January 25, 2013, the content of some presentations from the consultant did not consider the national political sentiment of the moment. Thus, Seven50 became a topic of partisan debate by some participants. From that point to the end of the process, a significant part of the work effort was consumed by additional public meetings and debates about the significance of the process and participation. During interviews with key administrators and consultants there was a shared sense that the public information effort should have been even more extensive and methodical. This conclusion was due in part to certain public opposition that grew in the northern counties as the plan neared completion.

As it was pointed out during interviews, the general tone of national politics associated with the mid-term election of 2012 played a role, as Seven50 was portrayed as a project of the Obama administration. The irony, of course, was the contrast between short-term interest of national political debates and the long-term aspirations of the plan. Electoral politics were quickly forgotten, as the next election cycle came around. A regional plan was intended to influence many such cycles.

\subsection{The Value of Seven50}

Final deliverables were accepted by the executive committee and distributed publicly in early 2014. People from different areas of the region reacted in contrasting ways. Some embraced the tools that most applied to their circumstances. Others rejected the recommendations immediately. The Commissions of Indian River County, St. Lucie County and Martin County voted to end their participation in the project.

As Seven50 was a voluntary and advisory plan, and had no regulatory component, its only value was as a repository of useful ideas. The final products attempted to catalogue all the input and recommendations. The best format for delivery of this information was the Seve50.org website. It provided an easily accessible summary of a very complex set of ideas, organized by topic. From the interviews, it became clear that two aspects of the plan were expected to have greater impact on the future. One was the toolkit. Each topic was illustrated with graphics, photographs and renderings that emphasized practical solutions that would contribute to the future prosperity of the region. The tools ranged the full scale and scope of regional planning, and provided implementation ideas for future work for local organizations, private industry and regional agencies.

A second valuable aspect of the Seven50 process consisted on discussions about governance. This was only a "conversation" because no specific strategies emerged from the plan, but all key administrators and consultants stated that they learned much during the process. Some expressed surprise at the realization that smaller counties to the north had very different priorities than the larger counties to the south. Thus, the public input process questioned the accepted narrative about growth, which suggested that development moved inexorable to the north along parameters established by the private sector. A more localized approach was requested by many participants.

\subsection{Seven50, Lessons Learned}

Seven50 failed to persuade countless local officials, civic leaders and businessmen that seven counties would be a single region for the next fifty years. In spite of three decades of multijurisdictional planning efforts by the Regional Planning Councils, the message of regionalism did not have a defined audience. For too long, decisions about development had been carried out at the local level, with great efficiency but questionable long-term effectiveness. In 2015, most participants interviewed expressed relief that the process was over. In the view of 
some key participants, political controversies, mostly short lived partisan rhetoric out of place in a fifty year timeframe, had overshadowed the initial optimism of public planning at the scale of the region.

Some key observations on theory and practice for future planning activities were common throughout the interviews:

1. Provide information and promote communication. Regional planning is not a common or intuitive activity. The process needed to be explained and the outcomes had been shared throughout the process. Seven50 attempted to do this, but efforts proved insufficient. Governance requires some common goals and fundamental consensus. A good plan is more than a collection of good ideas. It is also a vision accepted by stakeholders. Seven50 failed to communicate effectively.

2. Build partnerships. A region emerges from the political synergy of multiple local entities. Seven50's consortium was a very good start, but the scope of the effort was underestimated. More time and resources should have been devoted to this task. In particular, the timeframe needed to strengthen relationships was underestimated by project leaders.

3. Do not compromise the vision. Initially, the consultant team was very strong on this aspect of the project, which centered on conceptual ideas and technical solutions. Yet, many participants interviewed believed that the final document was edited excessively, as a result the review process. As the Plan was a voluntary document, without regulatory authority, its value depended on ideas. All ideas should had been collected and incorporated into the Plan. Whether they would be implemented or not would be determined at a later date, as needs and priorities of each local government were assessed. An incomplete vision, in a fifty year plan, would be of limited use.

4. Allow the democratic process to work. The Summits and presentations did not encourage public discussion, as the format emphasized formal presentations by consultants or speeches by public officials. Although some technological tools were used to gather real-time responses from the public, interaction was excessively controlled by facilitators. In the end, too much time was spent on lectures and not enough in conversation. A more participatory format may have led to consensus and political support, even within the political context of the time. Project leaders did not engage public debate in time, to the detriment of the overall effort.

5. The real topic was governance. Discussions of governance should have been at the core of the Seven50 process. Project leaders attempted to guide the conversation with tables and charts that described the complexity and inefficiency of regional activities. However, unresolved political debate about the fundamental assumptions of the project (one region, 50 years) prevented work towards policy and organizational solutions.

\section{Conclusion}

The final summit of Seven50 was hosted on January 15, 2014. The title of the event was “A Time to Lead”. The agenda focused on implementation. Public officials from places throughout the region spoke at length. A slick eighteen minute promotional video prepared by the public relations consultant summarized the findings and the tone of the project: serious issues, but mostly attractive footage from South Miami Beach, Key West, West Palm Beach and other evocative destinations, a few dramatic before and after aerial photographs of suburban sprawl throughout the region, smiling people bicycling and eating at outdoor restaurants, and brief statements from many project consultants and members of the Executive Committee describing their daily life and reaffirming "this is the Plan". Towards the end of the video, Michael Busha concluded the process itself had been the most important achievement. Finally, the credits listed in small print the South Florida Regional Partnership Members. "The Plan" mentioned in the video was an attractive summary of current planning ideas about town planning and sustainable development, with a hint of the need for enhanced governance.

Although Seven50 may have expanded the theory and methodology of regional planning, its lasting value may be as the initial step to better regional governance. The plan highlighted connections and provided direction. The mechanics of governance deserved to be explored in as much detail, and with similar conviction, as the planning vision for climate change or walkable communities. Effective implementation of the Seven50 toolkit would depend on the details of efficient regional administration at all scales of development. Such details were yet to be formulated as the Plan was delivered.

The "Seven50: Southeast Florida Prosperity Plan" report was published on March 18, 2014 in the form of a book, an old fashioned format that should survive five decades. In time, the book may be appreciated it on its 
own terms, as a timeless repository of ideas for prosperity and quality of life. As the struggles and shortcomings of the process are forgotten, the content of the Plan will remain unchanged, and may lead future public administrators towards better governance for better civic life.

\section{Endnote}

This is a revised version of a paper entitled "Seven50 Southeast Florida Prosperity Plan" that the co-authors presented at the UAA $45^{\text {th }}$ annual conference in Miami, Florida in April 2015. In-depth qualitative interviews were conducted with:

Jim Murley, Project Director;

Michael Busha, Executive Director, TCRPC;

Victor Dover, Lead Consultant;

Jason King, Consultant's project director;

Andrew Georgiadis, Consultant;

Elizabeth Plater-Zyberk, Consultant;

Tom Gustafson, Executive Committee.

\section{References}

Barnett, J. (2000). Planning for a New Century. Washington, DC: Island Press.

Calthorpe, P., \& Fulton, W. (2001). The Regional City. Washington, DC: Island Press.

Calthorpe, P. (2011). Urbanism in the Age of Climate Change. Washington DC: Island Press. http://dx.doi.org/10.5822/978-1-61091-005-7

Duany, A., Speck, J., \& Lydon, M. (2010) The Smart Growth Manual. New York: McGraw Hill.

Treasure Coast Regional Planning Council (2014) Seven50 Plan. Stuart, FL: TCRPC.

Treasure Coast Regional Planning Council (1992) Strategic Regional Policy Plan. Stuart, FL: TCRPC. 